\title{
The relationship between childhood adversity, recent stressors, and depression in college students attending a South African university
}

Sumaya Mall ${ }^{1,2^{*}}$ D, Philippe Mortier ${ }^{3}$, Lian Taljaard ${ }^{4,5}$, Janine Roos $^{5}$, Dan J. Stein ${ }^{1,4}$ and Christine Lochner ${ }^{4}$

\begin{abstract}
Background: College students are at risk of depression. This risk may be increased by the experience of childhood adversity and/or recent stressors. This study examined the association between reported experiences of childhood adversity, recent stressors and depression during the last 12 months in a cohort of South African university students.

Methods: Six hundred and eighty-six first year students at Stellenbosch University in South Africa completed a healthfocused e-survey that included items on childhood adversity, recent stressors and mood. Individual and population attributable risk proportions (PARP) between experiences of childhood adversity and 12-month stressful experiences and 12-month depression were estimated using multivariate binomial logistic regression analysis.

Results: About one in six students reported depression during the last 12 months. Being a victim of bullying and emotional abuse or emotional neglect during childhood were the strongest predictors of depression in the past year at both individual and population level. With regard to recent stressors, a romantic partner being unfaithful, serious ongoing arguments or break-ups with some other close friend or family member and a sexual or gender identity crisis were the strongest predictors of depression. The predictor effect of recent stressors was significantly reduced in the final model that adjusted for the type and number of childhood traumatic experiences. At a population level, academic stress, serious ongoing arguments or break-ups with a close friend or family member, and serious betrayal by someone close were the variables that yielded the highest PARP.
\end{abstract}

Conclusions: Our findings suggest a significant relationship between early adversity, recent stressors, and depression here and throughout, consistent with the broader literature on predictors of depression. This study contributes to the limited data on college students' mental health in low and middle income countries including on the African continent. The findings provide information on the population level effect sizes of trauma as a risk factor for depression, as well as on the relationship between specific recent stressors and depression in college students.

Keywords: College students, Depression, Childhood adversity, Recent Stressors, South Africa

\footnotetext{
* Correspondence: Sumaya.mall@gmail.com

${ }^{1}$ Department of Psychiatry and Mental Health, University of Cape Town, Cape

Town, South Africa

${ }^{2}$ Division of Epidemiology and Biostatistics, School of Public Health,

University of the Witwatersrand, Johannesburg, South Africa

Full list of author information is available at the end of the article
}

(c) The Author(s). 2018 Open Access This article is distributed under the terms of the Creative Commons Attribution 4.0 International License (http://creativecommons.org/licenses/by/4.0/), which permits unrestricted use, distribution, and reproduction in any medium, provided you give appropriate credit to the original author(s) and the source, provide a link to the Creative Commons license, and indicate if changes were made. The Creative Commons Public Domain Dedication waiver (http://creativecommons.org/publicdomain/zero/1.0/) applies to the data made available in this article, unless otherwise stated. 


\section{Background}

Several studies suggest that exposure to early childhood adversity or recent stressors (i.e. experiences during adulthood) are associated with increased risk of depression during adolescence or adulthood [1-4]. Not only could specific experiences of such adversity during childhood (e.g. physical abuse) increase the risk of depression in adulthood more significantly than others [5-8], but repeated trauma exposure may result in more severe symptoms of psychopathology $[9,10]$. Further, research has suggested that cumulative stressful experiences, i.e. experience of childhood adversity and recent stressors may interact to increase the risk of depression in adulthood $[11,12]$.

Although research suggests that depression is common among college students $[13,14]$ and that childhood adversity may be associated with psychopathology (e.g. depression or alcoholism) in this group [15, 16], several gaps remain in the field. First, a recent metaanalysis of mental health interventions for college students suggests that previous studies of this group have been restricted to higher income countries suggesting a need to conduct studies in low and middle income countries including on the African continent [17]. Second, to our knowledge, no studies have examined population level effect sizes of trauma as risk factor of depression in college students. These population effects can be calculated with population attributable risk proportions (PARP). Assuming a causal relationship between risk factors and outcome, PARPs provide an estimate of the potential reduction in depression prevalence should a particular risk factor be removed from the population $[18,19]$. They take into account that highly prevalent risk factors carrying low individuallevel risk may be as important to consider as low prevalent risk factors carrying high risk for the affected individuals. Third, while previous studies suggest that a summary score of recent stressors may well be predictive of depression, particularly among adolescents, there is less research on whether specific recent stressors are stronger predictors of depression than others [20,21].

Here we address these gaps in the literature in a study of a cohort of undergraduate students in South Africa. We hypothesized that in this group, 1) there would be a positive association between depression (i.e. in the last 12 months) and the number of childhood adverse and recent stressors experienced, 2) that different types of childhood trauma and recent stressors may be more significant in terms of their role in depression than others, 3) having any childhood adversity or any recent stressor has a significant role in predicting depression (i.e. in the last 12 months). Finally, we also aimed to calculate PARP, the rationale for which has been provided above [22].

\section{Methods}

\section{Aims}

This study, conducted at one university in South Africa, is embedded in an international, multi-site investigation into the wellness of undergraduate students known as the World Health Organization (WHO) World Mental Health Initiative Surveys International College Student Project (WMH-ICS). This parent study is an epidemiological study that aims to determine the prevalence and correlates of psychiatric disorders among college students in several participating nations. The WMH-ICS also aims to investigate and highlight paths to mental healthcare undertaken by students, and to encourage and promote treatmentseeking behavior [23].

\section{Study design, setting and participants}

The study was conducted at Stellenbosch University (SU), a public research university $40 \mathrm{~km}$ from Cape Town. In 2015, when data collection took place, more than half the students were white and females.

The data presented are cross-sectional data. All first year students who entered SU for the first time in 2015 received an email in March of that year, inviting them to participate in this study. A link to the e-survey with questions about lifetime history of risk and protective factors for negative outcomes, such as academic, mental and physical health problems (including past experience of those outcomes) were included. Students received monthly reminders of the survey between March 2015 and November 2015. Data collection ceased in November 2015.

Only students aged 18 or older, who provided informed consent (see below for more details), were allowed to progress into the survey.

All first year students at SU in $2015(n=5338)$ were invited to participate in this study. Our sample consisted of 686 participants $(12.9 \%$ of the original invited sample). Of these 377 were female $(54.9 \%)$ and 309 were male $(45.1 \%)$. With regard to ancestry, $66.3 \%$ of participating students were white, $18.9 \%$ 'coloured' ${ }^{1}, 12.1 \%$ were black and $2.7 \%$ of Indian descent (See Table 1 below for percentages weighted by gender and race).

\section{Materials and measures}

Several measures were employed in the survey. Those relating specifically to trauma, recent stressors and depression are described below:

\section{Childhood adversity}

Selected items from validated instruments including: the CIDI-3.0 childhood section [24], The Adverse Childhood Experiences International Questionnaire (ACE-IQ) [25] 
Table 1 Sociodemographic characteristics of the sample

\begin{tabular}{llll}
\hline Covariate & $\mathrm{n}(\mathrm{w})^{\mathrm{a}}$ & $\%(\mathrm{w})^{\mathrm{a}}$ & SE \\
\hline Gender & & & \\
Male & 309 & 45.1 & 1.9 \\
Female & 377 & 54.9 & 1.9 \\
Race & & & \\
White & 455 & 66.3 & 1.7 \\
Coloured & 129 & 18.9 & 1.5 \\
Black & 83 & 12.1 & 1.1 \\
Indian & 18 & 2.7 & 0.5 \\
\hline
\end{tabular}

aweighted for gender and race

and the Bully Survey [26], were employed to measure adverse experiences prior to the age of 17 . The domains that were extracted from the (ACE-IQ) explore several different experiences of childhood adversity including a) parental psychopathology (e.g. 'One of your parents (or the people who raised you) had a serious emotional or mental health problem, b) intimate partner violence during adolescence (e.g. How often were you in a romantic relationship where your partner repeatedly said hurtful or insulting things to you?, c) sexual assault (e.g. 'You were sexually abused at home') and physical assault, ('e.g. You were physically abused at home') d) emotional abuse (e.g. You felt loved and cared for by your family), e) bullying (e.g. How often were you bullied at school verbally (i.e., teased, called names)? and f) emotional and physical neglect (e.g. 'You had to do chores too hard and dangerous for someone your own age'). For the most part, our measures specifically ask about family-related adversity (e.g. physical assault perpetrated by a family member). Questions about sexual assault are not restricted to assault by family members, but include questions about assault by any perpetrator. All experiences are measured on a Likert scale of 1-5 where 1 indicates 'never', 2 indicates 'rarely', ' 3 indicates sometimes' 4 indicates 'often' and ' 5 ' indicates 'very often'. For meaningful comparisons between exposed and unexposed groups at both individual level and PARP analysis, the dichotomously coded variables were set at "rarely" for all items, except for bullying for which the cut-off value was set at "sometimes". These scores were consistent with previous WMHS studies [27, 28].

\section{Recent stressful experiences}

Questions about recent stressors were adapted from the Life Events Questionnaire (LEQ) [29], which has been shown to possess sound psychometric properties [30]. The LEQ dichotomously assesses the experience of threatening events that occurred during the previous 12 months. Recent stressors or stressful experiences were defined as the occurrence of a stressful event in the last 12 months. Twenty recent stressors were measured in the questionnaire. These included, but were not limited to, serious illness, death of a friend, romantic relationship difficulties, academic stress, sexual and gender identity crisis, unwanted pregnancy, HIV diagnosis, legal difficulties or being involved in crime.

\section{Depression occurring in the past year}

We selected three items to measure depression and (from sub-syndromal depression to major depressive disorder) to carefully estimate the burden of this disorder among college students. These criteria are based on the DSM-5 criteria and take into account that depression symptoms lie on a spectrum from symptoms to minor depression to the full disorder [31-34]. This broad concept of depression refers to individuals who have two or more (but less than five) symptoms of depression that have endured for at least two weeks and that are associated with impairment [35]. Respondents were asked to report the experience or frequency of the following symptoms in the past year: depressed mood ('how often did you feel sad or depressed'), low interest ('how often did you take little or no interest and pleasure in things') and interference in their daily activities ('how often did you feel so low that it interfered with your work or personal life?') on a Likert scale of $1-5$, ranging from "None of the time" (1) to "All or almost all of the time" (5). If they reported two core symptoms and interference in their work or daily lives 'sometimes' or more, they were categorized as having 'broad depression' [36]. We extracted reports of depression in the past year to associate more closely in time with recent stressful experiences. As described above, the recent stressful experiences had been reported as occurrences during the past year.

\section{Ethical issues}

After permission for conducting the study was obtained from the Institutional Review Board of SU and the University's Institutional Research and Planning Division, an email using the students' university email addresses, was sent to all first year students with a description of the study and a link to the e-survey.

In the invitation, students were informed that their participation in the survey was completely voluntary and that their responses would be treated as confidential. They were also informed that the survey results would be anonymous, that there may be potential discomforts (i.e. fatigue, inconvenience) and that there may also be benefits (i.e. contribution to generalizable knowledge). It was also emphasized that the students can withdraw from participation, with no negative consequences. However, due to the anonymity of the survey, they were notified that they will not be able to withdraw from the survey once they had submitted their responses. 
Students were also made aware that they will be contacted in subsequent (pre-graduate) years for a follow-up survey.

A phone number to a general study helpdesk was included in the informed consent for students who had questions or concerns. Students who were distressed or requiring urgent assistance were provided with contact details of the $24 \mathrm{~h}$ Crisis Line of the local Centre for Student Counselling and Development (CDSC) and the Mental Health Information Centre of Southern Africa. Participants were not able to complete the survey more than once.

Students were not paid to complete the survey. There was however an incentive to compete for a cash prize of 1000 South African rand (approximately 72,8 US dollars).

\section{Data analysis}

All analyses were conducted with SAS (version 9.4).

Nonresponse propensity weighting [37] was employed to account for nonresponse bias (i.e. potential differences in prevalence of depression between survey respondents and non-respondents) [38]. Nonresponse propensity weights were calculated using socio-demographic variables available for the full student population (i.e. race and gender of first year students). A logistic model was developed to predict survey response (vs. nonresponse), with gender and race as predictors. There is little variation in age of first year students so we did not include age as a predictor in these models. Based on this multivariable regression equation, predicted probabilities were calculated.
Final non-response propensity weights were obtained by taking the inverse of the predicted probabilities, followed by a normalization procedure to reassure that the sum of the final weights matches the actual sample size. Prevalence estimates are reported as weighted numbers, weighted proportions, and associated standard errors. Logistic regression procedures were used to explore the individual-level associations between predictors (i.e., childhood-adolescent traumatic experiences, and 12month recent stressors) and the outcome variable (i.e., having depression in the last 12 months). Parameter estimates are reported as odds ratios (OR) and associated 95\% confidence intervals. Apart from the specific type of traumatic or stressful experience, we also investigated the association between the presence of any experience in each risk domain under study, and 12-month depressive symptoms, as well as the number of specific experiences (categorized into having 1,2, or 3 or more experiences with zero as the reference category) in each risk, and depression over the last 12 months. All analyses were (additionally) adjusted for gender and race as suggested by previous research examining mental health of college students $[39,40]$. To estimate population-level risk for 12month depression, PARP proportions [22] were calculated for each predictor under study, using as a summary predictor the probabilities resulting from the logistic regression equations $[41,42]$. PARP provides an estimate of how many outcome cases (i.e., students with depression) are associated with a particular predictor variable under study. As such, assuming a causal relationship between predictor

Table 2 Childhood-adolescent adversity as bivariate predictors for the onset of depression during the past year

\begin{tabular}{|c|c|c|c|c|c|c|c|c|c|c|c|c|c|c|}
\hline \multirow[b]{2}{*}{ Predictor } & \multicolumn{7}{|c|}{ prevalence } & \multicolumn{3}{|c|}{ Chi-square test } & \multicolumn{3}{|c|}{ Odds Ratio $^{e}$} & \multirow{2}{*}{$\begin{array}{l}\text { PARP } \\
\%(W)\end{array}$} \\
\hline & $n(w)$ & $\%(w)^{a}$ & SE & $\%(w)^{b}$ & SE & $\%(w)^{c}$ & SE & $x_{2}$ & $\mathrm{df}$ & $P$-value ${ }^{d}$ & $\mathrm{OR}$ & $95 \%-$ & $95 \%+$ & \\
\hline Parental psychopathology & 308 & 47.6 & 1.9 & 44.7 & 2.1 & 60.8 & 4.4 & 9.03 & 1 & 0.002 & 2.1 & 1.3 & 3.2 & 26.7 \\
\hline Physical abuse & 134 & 20.4 & 1.5 & 19.1 & 1.7 & 25.5 & 4.0 & 2.22 & 1 & 0.139 & 1.8 & 1.1 & 3.1 & 9.3 \\
\hline Emotional abuse & 240 & 37.2 & 1.8 & 31.9 & 2.0 & 57.0 & 4.5 & 23.63 & 1 & $<0.001$ & 3.2 & 2.0 & 5.0 & 34.3 \\
\hline Sexual abuse & 28 & 4.4 & 0.7 & 3.3 & 0.7 & 9.0 & 2.4 & 7.06 & 1 & 0.006 & 3.0 & 1.3 & 7.1 & 5.2 \\
\hline Neglect & 84 & 12.9 & 1.3 & 10.6 & 1.3 & 22.6 & 3.8 & 11.39 & 1 & 0.001 & 3.4 & 1.9 & 6.0 & 13.0 \\
\hline Bullying victimization & 324 & 50.0 & 1.9 & 45.2 & 2.1 & 70.7 & 4.1 & 22.36 & 1 & $<0.001$ & 3.0 & 1.9 & 4.8 & 41.3 \\
\hline Dating violence & 102 & 15.7 & 1.3 & 13.8 & 1.4 & 24.6 & 3.8 & 7.75 & 1 & 0.005 & 1.9 & 1.2 & 3.3 & 9.8 \\
\hline Any adverse experience & 484 & 79.4 & 1.6 & 76.4 & 1.8 & 93.6 & 2.4 & 14.52 & 1 & $<0.001$ & 4.6 & 2.0 & 10.4 & 67.9 \\
\hline No adverse experience & 126 & 20.6 & 1.6 & 23.6 & 1.8 & 6.4 & 2.4 & - & - & - & (ref) & (ref) & (ref) & (ref) \\
\hline Exactly one adverse experience & 165 & 27.1 & 1.7 & 28.5 & 1.9 & 23.4 & 3.9 & - & - & - & 2.9 & 1.2 & 7.0 & 14.1 \\
\hline Exactly two adverse experiences & 126 & 20.6 & 1.6 & 21.2 & 1.8 & 18.5 & 3.6 & - & - & - & 3.5 & 1.4 & 9.0 & 12.1 \\
\hline Three or more adverse experiences & 194 & 31.7 & 1.8 & 26.7 & 1.9 & 51.7 & 4.6 & 28.98 & 3 & $<0.001$ & 8.0 & 3.4 & 18.8 & 42.3 \\
\hline
\end{tabular}

All OR and PARP estimates are adjusted for gender and race. Significant $P$-values, OR and PARP are indicated in bold $(a=0.05)$; OR $=$ odds ratio; PARP $=$ populationattributable risk proportion

${ }^{a}$ The prevalence of the predictor in the full sample

${ }^{b}$ The prevalence of the predictor among those without 12-month depressive symptoms

'The prevalence of the predictor among those with 12-month depressive symptoms

dUnadjusted for multiple comparison. For multiple test adjusted $P$-values, see Additional file 1: Table S1

${ }^{\mathrm{e}}$ Adjusted for gender and race 
and outcome, PARP can be considered as an estimate of the proportion of 12-month depression that could be potentially alleviated if (the impact of) a particular predictor variable was removed from the population. It should be pointed out, however, that similar to individual-level estimates of risk (OR), PARP estimates in our cross-sectional research design are flawed by the inability to establishing temporality between predictor and outcome, and by the inability to take into account potentially important confounder variables. As with OR, all PARP estimates were adjusted for gender and population group. Finally, a series of multivariable models were estimated. Predictors were entered in blocks, beginning with recent stressors, and followed by childhood-adolescent traumatic experiences, giving us the opportunity to look at the cumulative effect of childhood trauma and recent stressful experiences. Our initial objective was to include all predictor variables under study in the final multivariate models. However, due to estimation problems related to data sparseness, low-prevalent predictor variables $(n<30$; prevalence $<5 \%)$ were eliminated. Nagelkerke pseudo- $\mathrm{R}^{2}$ was used as a measure of total effect size, and Area-under-the-Curve as measure of prediction accuracy [43]. Firth's penalized likelihood estimation was consistently applied to avoid inconsistent estimators due to data sparseness [44].

\section{Results}

Prevalence estimates of socio-demographic variables

The prevalence of depression over the last 12 months was estimated at $16.1 \%$ with an associated standard error (SE)

Table 3 Recent stressors as bivariate predictors for the onset of depression during the past year, adjusted for gender and race

\begin{tabular}{|c|c|c|c|c|c|c|c|c|c|c|c|c|c|c|}
\hline \multirow[b]{2}{*}{ Predictor } & \multicolumn{7}{|c|}{ prevalence } & \multicolumn{3}{|c|}{ Chi-square test } & \multicolumn{3}{|c|}{ Odds Ratio $^{\mathrm{e}}$} & \multirow{2}{*}{$\begin{array}{l}\text { PARP' } \\
\%(w)\end{array}$} \\
\hline & $n(w)$ & $\%(w)^{a}$ & SE & $\%(w)^{b}$ & SE & $\%(w)^{c}$ & SE & $x_{2}$ & $\mathrm{df}$ & $P$-value ${ }^{\mathrm{d}}$ & $\mathrm{OR}$ & $95 \%-$ & $95 \%+$ & \\
\hline $\begin{array}{l}\text { A life-threatening illness or injury of a very close friend or } \\
\text { family member }\end{array}$ & 161 & 24.2 & 1.6 & 24.7 & 1.8 & 22.5 & 3.7 & 0.24 & 1 & 0.622 & 0.8 & 0.5 & 1.4 & -3.3 \\
\hline Death of a close friend or family member & 179 & 26.8 & 1.6 & 28.1 & 1.9 & 21.5 & 3.7 & 1.89 & 1 & 0.165 & 0.7 & 0.4 & 1.2 & -6.2 \\
\hline Break-up with a romantic partner & 202 & 30.5 & 1.7 & 29.0 & 1.9 & 37.7 & 4.4 & 3.11 & 1 & 0.074 & 1.5 & 1.0 & 2.3 & 10.1 \\
\hline You discovered that a romantic partner cheated on you & 73 & 11.0 & 1.2 & 9.6 & 1.2 & 19.7 & 3.6 & 8.97 & 1 & 0.003 & 2.4 & 1.3 & 4.3 & 9.1 \\
\hline Serious betrayal by someone else close to you & 141 & 21.2 & 1.5 & 18.7 & 1.6 & 34.7 & 4.2 & 13.43 & 1 & $<0.001$ & 2.1 & 1.3 & 3.4 & 15.1 \\
\hline $\begin{array}{l}\text { Serious ongoing arguments or break-ups with some } \\
\text { other close friend or family member }\end{array}$ & 136 & 20.6 & 1.5 & 17.1 & 1.6 & 35.2 & 4.3 & 17.85 & 1 & $<0.001$ & 2.5 & 1.6 & 4.1 & 18.0 \\
\hline Academic stress & 525 & 78.6 & 1.5 & 76.4 & 1.8 & 88.2 & 2.9 & 7.12 & 1 & 0.007 & 2.1 & 1.1 & 3.9 & 39.6 \\
\hline Sexual/Gender Identity Crisis & 47 & 7.0 & 1.0 & 6.0 & 1.0 & 14.0 & 3.1 & 8.29 & 1 & 0.004 & 3.3 & 1.7 & 6.7 & 7.6 \\
\hline Hospitalization & 65 & 9.8 & 1.1 & 9.2 & 1.2 & 14.6 & 3.2 & 2.83 & 1 & 0.092 & 1.7 & 0.9 & 3.2 & 4.7 \\
\hline You were involved in a life-threatening accident & 28 & 4.2 & 0.8 & 4.2 & 0.8 & 4.1 & 1.9 & 0.01 & 1 & 0.941 & 1.1 & 0.4 & 3.1 & 0.2 \\
\hline You were seriously physically assaulted & 25 & 3.7 & 0.7 & 3.3 & 0.8 & 4.5 & 2.1 & 0.38 & 1 & 0.569 & 2.2 & 0.7 & 6.3 & 2.0 \\
\hline You were sexually assaulted or raped & 3 & 0.5 & 0.2 & 0.3 & 0.2 & 0.8 & 0.8 & $f$ & - & 0.126 & 2.0 & 0.2 & 25.0 & 0.5 \\
\hline You had trouble with the police & 14 & 2.2 & 0.6 & 2.2 & 0.6 & 1.1 & 1.0 & 0.52 & - & 0.497 & 1.1 & 0.2 & 6.5 & 0.2 \\
\hline You spent time in jail & 2 & 0.4 & 0.2 & 0.4 & 0.3 & - & - & $f$ & - & 1.000 & 1.7 & 0.0 & 62.7 & 0.1 \\
\hline Serious legal problem & 9 & 1.4 & 0.5 & 1.5 & 0.5 & - & - & $f$ & - & 0.612 & 0.4 & 0.0 & 8.7 & -0.5 \\
\hline You had a pregnancy & 2 & 0.3 & 0.2 & - & & 1.6 & 1.1 & $f$ & - & 0.032 & 14.5 & 0.3 & 699.7 & 1.0 \\
\hline You were diagnosed with a sexually transmitted infection & 2 & 0.3 & 0.2 & 0.2 & 0.1 & 1.2 & 1.1 & $f$ & - & 0.323 & 8.6 & 0.5 & 144.5 & 0.7 \\
\hline You were diagnosed with HIV & 0 & 0.0 & - & - & - & - & - & - & - & - & - & - & - & - \\
\hline Any other recent experience & 70 & 10.6 & 1.2 & 8.7 & 1.2 & 17.9 & 3.5 & 7.90 & 1 & 0.005 & 2.4 & 1.3 & 4.4 & 8.8 \\
\hline Any recent experience & 552 & 90.7 & 1.2 & 89.2 & 1.4 & 96.1 & 1.8 & 4.34 & 1 & 0.037 & 2.4 & 0.9 & 6.6 & 49.6 \\
\hline No recent experience & 57 & 9.3 & 1.2 & 10.8 & 1.4 & 3.9 & 1.8 & - & - & - & (ref) & (ref) & (ref) & (ref) \\
\hline Exactly one recent experience & 133 & 21.9 & 1.6 & 23.5 & 1.8 & 13.1 & 3.0 & - & - & - & 1.2 & 0.4 & 3.9 & 2.4 \\
\hline Exactly two recent experiences & 147 & 24.2 & 1.7 & 24.4 & 1.9 & 25.0 & 4.1 & - & - & - & 2.3 & 0.8 & 6.7 & 12.4 \\
\hline Three or more recent experiences & 271 & 44.6 & 1.9 & 41.3 & 2.1 & 57.9 & 4.6 & 13.00 & 3 & 0.004 & 3.1 & 1.1 & 8.8 & 35.1 \\
\hline
\end{tabular}

Significant $P$-values, OR and PARP are indicated in bold $(a=0.05)$; OR Odds ratio, PARP Population- attributable risk proportion

${ }^{\text {a }}$ The prevalence of the predictor in the full sample

${ }^{\mathrm{b}}$ The prevalence of the predictor among those without 12-month depressive symptoms

${ }^{\mathrm{c}}$ The prevalence of the predictor among those with 12-month depressive symptoms

${ }^{d}$ Unadjusted for multiple comparison. For multiple test adjusted $P$-values, see Additional file 1: Table S1

${ }^{\mathrm{e}}$ Adjusted for gender and race

fFisher-Exact test 
Table 4 Multivariable Model adjusted for type and number of childhood-adolescent traumatic experiences

\begin{tabular}{|c|c|c|c|c|c|c|c|c|c|c|}
\hline \multirow[b]{2}{*}{ Predictor } & \multicolumn{5}{|c|}{ MODEL 1} & \multicolumn{5}{|c|}{ MODEL 2} \\
\hline & $\overline{\mathrm{OR}}$ & $95 \%-$ & $95 \%+$ & PARP & $P$-value ${ }^{a}$ & $\overline{\mathrm{OR}}$ & 95\%- & $95 \%+$ & PARP & $P$-value ${ }^{a}$ \\
\hline $\begin{array}{l}\text { A life-threatening illness or injury of a very close } \\
\text { friend or family member }\end{array}$ & 1.0 & 0.5 & 1.8 & -0.6 & 0.913 & 0.9 & 0.5 & 1.7 & -2.4 & 0.688 \\
\hline Death of a close friend or family member & 0.7 & 0.4 & 1.3 & -6.5 & 0.267 & 0.8 & 0.4 & 1.6 & -3.2 & 0.588 \\
\hline Break-up with a romantic partner & 1.0 & 0.6 & 1.8 & 0.2 & 0.974 & 1.1 & 0.6 & 2.0 & 1.7 & 0.819 \\
\hline You discovered that a romantic partner cheated on you & 2.1 & 1.0 & 4.3 & 7.7 & 0.048 & 1.9 & 0.8 & 4.2 & 5.9 & 0.137 \\
\hline Serious betrayal by someone else close to you & 1.2 & 0.7 & 2.2 & 4.2 & 0.499 & 0.9 & 0.5 & 1.7 & -2.1 & 0.731 \\
\hline $\begin{array}{l}\text { Serious ongoing arguments or break-ups with some } \\
\text { other close friend or family member }\end{array}$ & 2.0 & 1.1 & 3.6 & 13.0 & 0.023 & 1.7 & 0.9 & 3.3 & 9.2 & 0.113 \\
\hline Academic stress & 1.5 & 0.8 & 3.1 & 24.3 & 0.235 & 1.3 & 0.6 & 2.8 & 14.3 & 0.493 \\
\hline Sexual/Gender Identity Crisis & 3.0 & 1.3 & 6.8 & 6.9 & 0.008 & 2.0 & 0.7 & 5.2 & 3.4 & 0.168 \\
\hline Hospitalization & 1.7 & 0.8 & 3.4 & 4.3 & 0.154 & 2.0 & 0.9 & 4.5 & 5.1 & 0.076 \\
\hline Any other stressful event & 2.0 & 1.0 & 4.0 & 6.0 & 0.061 & 1.5 & 0.6 & 3.4 & 3.1 & 0.356 \\
\hline Exactly two recent stressful experiences & 1.4 & 0.7 & 3.0 & 6.1 & 0.359 & 1.3 & 0.6 & 2.9 & 4.2 & 0.541 \\
\hline Three or more recent stressful experiences & 1.0 & 0.4 & 2.9 & 0.3 & 0.987 & 0.8 & 0.3 & 2.6 & -6.2 & 0.764 \\
\hline Parental psychopathology & & & & & & 2.4 & 1.2 & 4.8 & 27.1 & 0.016 \\
\hline Physical abuse & & & & & & 0.8 & 0.4 & 1.7 & -3.8 & 0.502 \\
\hline Emotional abuse & & & & & & 3.3 & 1.5 & 7.1 & 31.2 & 0.003 \\
\hline Sexual abuse & & & & & & 0.8 & 0.2 & 2.8 & -0.8 & 0.762 \\
\hline Neglect & & & & & & 3.1 & 1.4 & 7.1 & 10.6 & 0.006 \\
\hline Bullying victimization & & & & & & 3.2 & 1.6 & 6.2 & 37.4 & 0.001 \\
\hline Dating violence & & & & & & 2.5 & 1.1 & 5.5 & 11.0 & 0.028 \\
\hline Exactly two childhood adverse experiences & & & & & & 0.5 & 0.2 & 1.4 & -10.3 & 0.194 \\
\hline Three or more childhood adverse experiences & & & & & & 0.3 & 0.1 & 1.3 & -35.8 & 0.116 \\
\hline
\end{tabular}

All analyses are adjusted for gender and race. Significant OR and PARP are indicated in bold ( $a=0.05)$; OR = odds ratio; PARP = population- attributable risk proportion. Nagelkerke pseudo R-square for the first model was $9.48 \%$; for the second model this was $15.02 \%$. Area under the Curve for the first model was 0.722 ; for the second model this was 0.790

a unadjusted for multiple comparison. For multiple test adjusted P-values, see Additional file 1: Table S2

of 1.3. Examining the prevalence of adverse events prior to the age of 17 suggested that $79.4 \%$ of respondents of the full sample (i.e. with or without depression) reported experiencing at least one childhood adverse event. The three most commonly reported childhood adverse events across the whole sample were bullying (50.0\%), emotional abuse (37.2\%) and parental psychopathology (47.6\%). With regard to recent recent stressors, almost all (90.7\%) participants in the whole sample reported experiencing at least one recent stressor. Academic stress was most common, with $78.6 \%$ of the students reporting this experience. Other recent stressors, albeit less common, include breaking up with a romantic partner $(30.5 \%)$ or the death of a close friend or family member $(26.8 \%)$.

\section{Bivariate correlates of 12-month depressive symptoms}

The following experiences of childhood adversity prior to the age of 17 were significantly associated with depression in the past year: parental psychopathology $(\mathrm{OR}=2.1 ; 95 \% \mathrm{CI}=1.3-3.2)$, emotional abuse $(\mathrm{OR}=$
3.2; $95 \% \mathrm{CI}=2.0-5.0)$, sexual abuse $(\mathrm{OR}=3.0 ; 95 \% \mathrm{CI}$ $=1.3-7.1)$, neglect $(\mathrm{OR}=3.4 ; 95 \% \mathrm{CI}=1.9-6.0)$, bullying $(\mathrm{OR}=3.0 ; 95 \% \mathrm{CI}=1.9-4.8)$ and dating violence $(\mathrm{OR}=1.9 ; 95 \% \mathrm{CI}=1.2-3.3)$. There was a clear doseresponse relationship between childhood adversity and depression. Having any adverse experience was associated with a 4.6 increased risk of depression $(\mathrm{OR}=4.6$; $95 \% \mathrm{CI}=2.0-10.4)$ with gender and race adjusted ORs ranging from 4.6 to 8.0 for three or more types of adversity (95\% $\mathrm{CI}=3.4-18.8)$. Having an experience of any adversity, three or more adversities and bullying yielded the highest PARP (ranging from $41.3 \%$ to 67.9\%) (See Table 2).

With regard to recent stressors, the following stressors were significantly associated with depression in the past year: discovery that a romantic partner had cheated (OR $=2.4 ; 95 \% \mathrm{CI}=1.3-4.3)$, serious betrayal by someone close to you $(\mathrm{OR}=2.1 ; 95 \% \mathrm{CI}=1.3-3.4)$, serious ongoing arguments or breakups with a close friend or family member $(\mathrm{OR}=2.5 ; 95 \% \mathrm{CI}=1.6-4.1]$, academic stress 
$(\mathrm{OR}=2.1 ; 95 \% \mathrm{CI}=1.1-3.9)$, sexual or gender identity crisis $(\mathrm{OR}=3.3$; 95\% $\mathrm{CI}=1.7-6.7)$ and 'other' recent experience $(\mathrm{OR}=2.4 ; 95 \% \mathrm{CI}=1.5-4.4)$. After disaggregation for the specific number of stressful experiences, we found evidence for an effect of three or more recent stressor $\quad(\mathrm{OR}=3.1 ; \quad 95 \% \quad \mathrm{CI}=1.1-8.8)$. From a population-level perspective, academic stress, three or more stressors and serious ongoing arguments were the variables that yielded the highest PARPs ranging from $18.0-39.6 \%$.

\section{Multivariable correlates of 12-month depression}

Finally, a series of multivariable models were estimated giving us the opportunity to look at childhood adversity and recent stressors cumulatively (See Table 3 ). A first model found that, when adjusting for both type and number of 12-month recent stressors, three 12-month recent stressors remained significantly associated with depressive symptoms, i.e., a romantic partner being unfaithful, serious ongoing arguments or break-ups with a close friend or family member and a sexual or gender identity crisis, with ORs ranging from 2.1-3.0, and PARPs ranging from $6.9-13.0 \%$. The effect of 12-month stressful events became non-significant in the final model (Nagelkerke pseudo- $\mathrm{R}^{2}=15.0 \%$; $\mathrm{AUC}=0.79$ ) that additionally adjusted for type and number of childhood traumatic experiences, though it is worth noting that the OR decrease was minimal (see Table 4).

\section{Discussion}

Our multivariable logistic regression model indicated that childhood adversity and three recent stressors were significantly associated with current depression in this cohort. Students reporting adverse events during childhood, which included neglect, emotional abuse and being bullied specifically, were about three times more likely to report current depression. From an individual- and population level perspective, emotional abuse and being bullied prior to the age of 17 were significantly associated to current depressive symptoms: The data indicate that roughly $32-38 \%$ of the reported depression in this cohort were attributable to these two types of adversities. With regard to recent stressors, the multivariable logistic regression model suggested that a romantic partner being unfaithful, serious ongoing arguments or break-ups with a close friend or family member and a sexual or gender identity crisis were the strongest predictors of depression during the past year.

These data are consistent with a broad range of studies indicating that experiences of childhood adversity like bullying [45] are associated with subsequent onset of psychopathology [46, 47]. Previous studies have also suggested that there is a dose-response relationship between childhood adversity and psychopathology [2, 48]. Similarly, the role of recent stressors in depression has been well explored in the literature $[49,50]$, with some evidence for the cumulative effect of childhood adversity and recent stressors [11, 51]. While several recent stressors have been found to be associated with depression, our adjusted multivariable model specifically found that gender identity crisis, a romantic partner being unfaithful and arguments within a family to be associated with depression. With regard to a gender identity crisis, a recent review by Turban and Ehrensaft [52] suggest that youth who experience gender identity crisis may be at risk of depression among other comorbid conditions. Similarly, terminating a romantic relationship has been found to be significantly linked to depression in several studies [53]. Reyes-Rodriguez and colleagues [54], who examined depression among a similar sample of college students in Puerto Rico, found that depression was associated with ending a romantic relationship [54]. Studies, albeit of adolescents and not college students, have suggested a plausible association between family arguments and depression $[55,56]$.

A number of important study limitations must be noted. First, the study was restricted to one university in South Africa, and we are not certain that the results do necessarily extrapolate to others. Second, a minority of the invitees completed the survey (12.9\%). However, the use of sophisticated weighting techniques adjusted for the missing data. Third, our data are cross-sectional, and attempts to derive causal relationships are tentative. Fourth, despite our attempts to establish a closer temporal link between recent stressors and depression in the last year, we still cannot be entirely sure if the event (e.g. family arguments) preceded the onset of depressive symptoms. Family arguments could be an antecedent or a consequence of depression, as suggested by previous studies $[57,58]$. Fifth, self-reports of childhood adversity may be subject to recall bias. Our survey was designed as a self-report and was completed without the assistance of an interviewer in an attempt to limit recall bias and to collect information that was as accurate as possible [59]. Sixth, our measures of childhood adversity and recent stressors may not however adequately capture the severity or duration of traumatic experiences [60]. Seventh, due to limited statistical power, we were unable to examine associations for sub-syndromal depression and major depressive disorder separately, and to include low-prevalent predictor variables in the final multivariate models. Larger sample sizes are needed to address these objectives in the future. Lastly, this is an exploratory study in which multiple analyses were undertaken without correction. Future confirmatory research should formally test the information this study generated. These phenomena deserve future study. 
Despite these limitations, our findings suggest that a history of some childhood adverse events and recent stressors are associated with depression in students attending a tertiary institution for the first time. This association may be particularly pronounced during the transitional period of adolescence to early adulthood, characteristic of the university/college years. Further retrospective and prospective studies with larger samples are needed to examine the interaction between trauma, stress and depression.

\section{Conclusions}

In conclusion, the college years are associated with increased risk of depression [61, 62]. Our findings suggest a significant relationship between early adversity, specific recent stressors, and depression in our student cohort, consistent with the broader literature on predictors of depression. Future research should address the impact of childhood trauma and recent stressors on wellbeing, quality of life, academic performance and choices after graduation. While this cross-sectional study underlines a number of variables that are associated with depression, longitudinal research is needed to fully delineate the relevant causal relationships. Universities could be natural sites of awareness campaigns of mental health related issues and intervention strategies and options, both at the prevention and treatment level [63]. First year students should be made aware of, and encouraged to make use of locally available mental health services for psycho-social support and to improve coping strategies.

\section{Endnotes}

${ }^{1}$ The South African Apartheid system created population categories including White, Black African, Indian and Coloured. The term 'Indian' refers to individuals whose ancestors are from India. The term 'Coloured' broadly refers to individuals of mixed ancestry. These categories are still used in census and statistical data; we use them here not in order to reify these sociocultural categories, but rather because we are interested in exploring potential health disparities between population groups.

\section{Additional file}

Additional file 1: Table S1. Adjusted $P$-values after adjustment procedures for multiple comparison (Tables $2 \& 3$ ). Table S2 Adjusted $P$-values after adjustment procedures for multiple comparison (Table 4). (DOCX $22 \mathrm{~kb}$ )

\section{Acknowledgements}

We wish to acknowledge the contributions of Professors Ronny Bruffaerts, KU Leuven, Belgium and Martin Kidd, Stellenbosch University, South Africa to the manuscript.

The first author (SM) has received post-doctoral research funding from the Harry Crossley Foundation and the National Research Foundation of South Africa while enrolled in a post-doctoral fellowship at the University of Cape Town.

We gratefully acknowledge the support of the Ithemba Foundation.
Availability of data and materials

The data that support the findings of this study are not publicly available as data collection is ongoing.

\section{Role of the sponsor}

The funding sources had no role in the design and conduct of the study; collection, management, analysis, interpretation of the data; preparation, review, or approval of the manuscript; and decision to submit the manuscript for publication. The views reflected in the manuscript are not necessarily the views of the funders.

\section{Authors' contributions}

All authors contributed to and have approved the final manuscript. SM, LT \& PM had full access to all of the data in this study and take responsibility for the integrity of the data, and the accuracy of the data analysis. Study concept and design: SM, LT, JR, DJS, PM \& CL. Acquisition, analysis, or interpretation of data: SM, LT, PM \& CL. Drafting of the manuscript: SM. Critical revision of the manuscript for important intellectual content: SM, LT, JR, DJS, PM \& CL.

Statistical analysis: PM. Administrative, technical, or material support: SM, LT, JR, DJS, PM \& CL. Study supervision: LT, JR \& CL.

Ethics approval and consent to participate

Ethical approval was granted by Stellenbosch University's Ethics Committee of the Faculty of Health Sciences.

Consent for publication

Consent for publication is not applicable in this study.

Competing interests

The authors declare that they have no competing interests.

\section{Publisher's Note}

Springer Nature remains neutral with regard to jurisdictional claims in published maps and institutional affiliations.

\section{Author details}

${ }^{1}$ Department of Psychiatry and Mental Health, University of Cape Town, Cape Town, South Africa. ${ }^{2}$ Division of Epidemiology and Biostatistics, School of Public Health, University of the Witwatersrand, Johannesburg, South Africa. ${ }^{3}$ Research Group Psychiatry, Department of Neurosciences, KU, Leuven, Belgium. ${ }^{4}$ MRC Unit on Risk and Resilience in Mental Disorders, Department of Psychiatry, Stellenbosch University, Stellenbosch, South Africa. ${ }^{5}$ Mental Health Information Centre of Southern Africa, Stellenbosch, South Africa.

Received: 24 May 2017 Accepted: 14 December 2017

Published online: 09 March 2018

\section{References}

1. Heim C, Newport DJ, Mletzko T, et al. The link between childhood trauma and depression: Insights from HPA axis studies in humans. Psychoneuroendocrinology. 2008;33:693-710. https://doi.org/10.1016/j.psyneuen.2008.03.008.

2. McLaughlin KA, Green JG, Gruber MJ, et al. Childhood adversities and adult psychiatric disorders in the national comorbidity survey replication II: associations with persistence of DSM-IV disorders. Arch Gen Psychiatry. 2010;67:124-32. https://doi.org/10.1001/archgenpsychiatry.2009.187.

3. Bruwer B, Govender R, Bishop M, et al. Association between childhood adversities and long-term suicidality among south Africans from the results of the south African stress and health study: a cross-sectional study. BMJ Open. 2014;4:-e004644. https://doi.org/10.1136/bmjopen-2013-004644.

4. Nanni V, Uher R, Danese A (2012) Childhood maltreatment predicts unfavorable course of illness and treatment outcome in depression: a meta-analysis. Am J psychiatry 169:141-151. https://doi.org/10.1176/Appi. Ajp.2011.11020335.

5. Lindert J, Von Ehrenstein OS, Grashow R, et al. Sexual and physical abuse in childhood is associated with depression and anxiety over the life course: systematic review and meta-analysis. Int J Public Health. 2014;59:359-72. https://doi.org/10.1007/s00038-013-0519-5.

6. Plaza A, Garcia-Esteve L, Torres A, et al. Childhood physical abuse as a common risk factor for depression and thyroid dysfunction in the earlier postpartum. Psychiatry Res. 2012;200:329-35. https://doi.org/10.1016/j.psychres.2012.06.032. 
7. Levitan $\mathrm{RD}$, Parikh SV, Lesage $\mathrm{AD}$, et al. Major depression in individuals with a history of childhood physical or sexual abuse: relationship to neurovegetative features, mania, and gender. Am J Psychiatry. 1998;155:1746-52. https://doi.org/ 10.1176/ajp.155.12.1746

8. Infurna MR, Reichl C, Parzer $P$, et al. Associations between depression and specific childhood experiences of abuse and neglect: a metaanalysis. J Affect Disord. 2016;190:47-55. https://doi.org/10.1016/j.jad. 2015.09.006.

9. Solomon Z, Bromet E. The role of social factors in affective disorder: an assessment of the vulnerability model of Brown and this colleagues. Psychol Med. 1982;12:123-30. https://doi.org/10.1017/S0033291700043361.

10. Park SC, Kim D, Jang EY. Prevalence and symptomatic correlates of interpersonal trauma in south Korean outpatients with major depressive disorder. Compr Psychiatry. 2016;66:46-52. https://doi.org/10.1016/j. comppsych.2015.12.006.

11. Suliman S, Mkabile SG, Fincham DS, et al. Cumulative effect of multiple trauma on symptoms of posttraumatic stress disorder, anxiety, and depression in adolescents. Compr Psychiatry. 2009;50:121-7. https://doi.org/ 10.1016/j.comppsych.2008.06.006.

12. Karam EG, Friedman MJ, Hill ED, et al. Cumulative traumas and risk thresholds: 12-month ptsd in the world mental health $(\mathrm{WMH})$ surveys. Depress Anxiety. 2014;31:130-42. https://doi.org/10.1002/da.22169.

13. Mortier P, Demyttenaere $K$, Auerbach RP, et al. The impact of lifetime suicidality on academic performance in college freshmen. J Affect Disord. 2015;186:254-60. https://doi.org/10.1016/j.jad.2015.07.030.

14. Beiter R, Nash R, McCrady M, et al. The prevalence and correlates of depression, anxiety, and stress in a sample of college students. J Affect Disord. 2015;173:90-6. https://doi.org/10.1016/j.jad.2014.10.054.

15. Goldstein AL, Flett GL, Wekerle C. Child maltreatment, alcohol use and drinking consequences among male and female college students: an examination of drinking motives as mediators. Addict Behav. 2010;35:636-9. https://doi.org/10.1016/j.addbeh.2010.02.002

16. Curran TA, Gawley E, Casey P, et al. Depression, suicidality and alcohol abuse among medical and business students. Ir Med J. 2009;102

17. Regehr C, Glancy D, Pitts A. Interventions to reduce stress in university students: a review and meta-analysis. J Affect Disord. 2013;148:1-11. https://doi.org/10.1016/j.jad.2012.11.026.

18. Booth KVP, Paunesku D, Msall M, et al. Using population attributable risk to help target preventive interventions for adolescent depression. Int J Adolesc Med Health. 2008;20:307-19.

19. Patel V, Maj M, Flisher AJ, et al. Reducing the treatment gap for mental disorders: a WPA survey. World Psychiatry. 2010;9:169-76. https://doi.org/10. 1002/j.2051-5545.2010.tb00305.x.

20. Schuler KL, Ruggero CJ, Goldstein BL, et al. Diurnal cortisol interacts with stressful events to prospectively predict depressive symptoms in adolescent girls. J Adolesc Health. 2017; https://doi.org/10.1016/j.jadohealth.2017.06.005.

21. LeMoult J, Ordaz SJ, Kircanski K, et al. Predicting first onset of depression in young girls: interaction of diurnal cortisol and negative life events. J Abnorm Psychol. 2015;124:850-9. https://doi.org/10.1037/abn0000087.

22. Krysinska K, Martin G. The struggle to prevent and evaluate: application of population attributable risk and preventive fraction to suicide prevention research. Suicide Life Threat Behav. 2009;39:548-57. https://doi.org/10.1521/ suli.2009.39.5.548.

23. Auerbach RP, Alonso J, Axinn WG, et al. Mental disorders among college students in the World Health Organization world mental health surveys. Psychol Med. 2016:1-16. https://doi.org/10.1017/S0033291716001665.

24. Kessler RC, Üstün BB. The world mental health $(\mathrm{WMH})$ survey initiative version of the World Health Organization (WHO) composite international diagnostic interview (CIDI). Int J Methods Psychiatr Res. 2004;13:93-117. https://doi.org/10.1002/mpr.168.

25. Felitti VJ, Anda RF, Nordenberg D, et al. Relationship of childhood abuse and household dysfunction to many of the leading causes of death in adults - impact on children. Am J Prev Med. 1998;14:14. https://doi.org/10. 1016/S0749-3797(98)00017-8

26. Swearer SM, Cary PT. Perceptions and attitudes toward bullying in middle school youth. J Appl Sch Psychol. 2003;19:63-79. https://doi.org/10.1300/J008v19n02_05.

27. Mortier $\mathrm{P}$, Kiekens $\mathrm{G}$, Auerbach RP, et al. A risk algorithm for the persistence of suicidal thoughts and behaviors during college. J Clin Psychiatry. 2017;78: e828-36. https://doi.org/10.4088/JCP.17m11485.

28. Nansel TR, Overpeck M, Pilla RS, et al. Bullying behaviors among US youth: prevalence and association with psychosocial adjustment. JAMA. 2001;285: 2094-100. https://doi.org/10.1001/jama.285.16.2094.
29. Brugha TS, Cragg D. The list of threatening experiences: the reliability and validity of a brief life events questionnaire. Acta Psychiatr Scand. 1990;82: 77-81. https://doi.org/10.1111/j.1600-0447.1990.tb01360.x.

30. Gray MJ, Litz BT, Hsu JL, Lombardo TW. Psychometric properties of the life events checklist. Assessment. 2004;11:330-41. https://doi.org/10.1177/ 1073191104269954.

31. Angst J, Sellar R, Merikangas KR. Depressive spectrum diagnoses. Compr Psychiatry. 2000;41:39-47. https://doi.org/10.1016/50010-440X(00)80007-3.

32. Judd LL, Akiskal HS. Delineating the longitudinal structure of depressive illness: beyond clinical subtypes and duration thresholds. Pharmacopsychiatry. 2000;33:3-7. https://doi.org/10.1055/s-2000-7967.

33. Andrews $\mathrm{G}$, Brugha $T$, Thase $M E$, et al. Dimensionality and the category of major depressive episode. Int J Methods Psychiatr Res. 2007; https:/doi.org/10.1002/ mpr.216.

34. Ayuso-Mateos JL, Nuevo R, Verdes E, et al. From depressive symptoms to depressive disorders: the relevance of thresholds. Br J Psychiatry. 2010;196: 365-71. https://doi.org/10.1192/bjp.bp.109.071191.

35. Karsten J, Hartman CA, Ormel J, et al. Subthreshold depression based on functional impairment better defined by symptom severity than by number of DSM-IV symptoms. J Affect Disord. 2010;123:230-7. https://doi.org/10. 1016/j.jad.2009.10.013

36. Sadek N, Bona J. Subsyndromal symptomatic depression: a new concept. Depress Anxiety. 2000;12:30-9. https://doi.org/10.1002/1520-6394(2000)12: $1<30:: A I D-D A 4>3.0 . C O ; 2-P$

37. Rosenbaum PR, Rubin DB (1983) a. "The central role of the propensity score in observational studies for causal effects" Biometrika. Biometrika 70 SRC-: 41-55. https://doi.org/10.1093/biomet/70.1.41.

38. Kiekens G, Claes L, Demyttenaere K, et al. Lifetime and 12-month nonsuicidal self-injury and academic performance in college freshmen. Suicide Life-Threatening Behav. 2016;46:563-76. https://doi.org/10.1111/sltb.12237.

39. Forke CM, Myers RK, Catallozzi M, Schwarz DF. Relationship violence among female and male college undergraduate students. Arch Pediatr Adolesc Med. 2008;162:634-41. https://doi.org/10.1001/archpedi.162.7.634.

40. Krupnick JL, Green BL, Stockton P, et al. Mental health effects of adolescent trauma exposure in a female college sample: exploring differential outcomes based on experiences of unique trauma types and dimensions. Psychiatry. 2004;67:264-79. https://doi.org/10.1521/psyc.67.3. 264.48986.

41. Bruffaerts R, Demyttenaere K, Borges $G$, et al. Childhood adversities as risk factors for onset and persistence of suicidal behaviour. Br J Psychiatry. 2010; 197:20-7. https://doi.org/10.1192/bjp.bp.109.074716.

42. Nock MK, Borges G, Bromet EJ, et al. Suicide and suicidal behavior. Epidemiol Rev. 2008;30:133-54. https://doi.org/10.1093/epirev/mxn002.

43. Hu B, Shao J, Palta M. Pseudo-R2 in Logistic Regression Model. Stat Sin. 2006:16:847-60

44. Firth D. Bias reduction of maximum likelihood estimates. Biometrika. 1993; 80:27-38. https://doi.org/10.1093/biomet/80.1.27.

45. Ttofi MM, Farrington DP. Risk and protective factors, longitudinal research, and bullying prevention. New Dir Youth Dev. 2012;2012:85-98. https://doi.org/10. 1002/yd.20009.

46. Clark C, Caldwell T, Power C, Stansfeld S. Does the influence of childhood adversity on psychopathology persist across the lifecourse? A 45-year prospective epidemiologic study. Ann Epidemiol. 2010;20:385-94. https://doi.org/10.1016/j.annepidem.2010.02.008.

47. Turner HA, Butler MJC-D. Direct and indirect effects of childhood adversity on depressive symptoms in young adults. J youth Adolesc. 2003;32:89-103. ST-direct and indirect effects of childh

48. Green JG, McLaughlin KA, Berglund PA, et al. Childhood adversities and adult psychiatric disorders in the national comorbidity survey replication I: associations with first onset of DSM-IV disorders. Arch Gen Psychiatry. 2010; 67:113-23. https://doi.org/10.1001/archgenpsychiatry.2009.186.

49. Kendler KS, Thornton LM, Gardner CO. Stressful life events and previous episodes in the etiology of major depression in women: an evaluation of the "kindling" hypothesis. Am J Psychiatry. 2000;157:1243-51. https://doi. org/10.1176/appi.ajp.157.8.1243

50. Kendler KS, Karkowski LM, Prescott CA. Causal relationship between stressful life events and the onset of major depression. Psychiatry Interpers Biol Process. 1999:156:837-41. https://doi.org/10.1176/ajp.156.6.837.

51. Comijs HC, Beekman ATF, Smit F, et al. Childhood adversity, recent life events and depression in late life. J Affect Disord. 2007:103:243-6. https://doi.org/10.1016/j.jad.2007.01.012. 
52. Turban $J$, Ehrensaft D. Research review: gender identity in youth: treatment paradigms and controversies. J Child Psychol Psychiatry. 2017; https://doi. org/10.1111/jcpp.12833.

53. Tao M, Li Y, Xie D, et al. Examining the relationship between lifetime stressful life events and the onset of major depression in Chinese women. J Affect Disord. 2011;135:95-9. https://doi.org/10.1016/j.jad.2011.06.054

54. Reyes-Rodríguez ML, Rivera-Medina CL, Cámara-Fuentes L, et al. Depression symptoms and stressful life events among college students in Puerto Rico. J Affect Disord. 2013;145:324-30. https://doi.org/10.1016/j.jad.2012.08.010.

55. Lin FG, Chou YC, CH W, Lin JD. Short-term and long-term influences of family arguments and gender difference on developing psychological well-being in Taiwanese adolescents. Res Dev Disabil. 2014;35:2735-43. https://doi.org/10.1016/j.ridd.2014.07.018.

56. Paradis AD, Reinherz HZ, Giaconia RM, et al. Long-term impact of family arguments and physical violence on adult functioning at age 30 years: findings from the Simmons longitudinal study. J Am Acad Child Adolesc Psychiatry. 2009;48:290-8. https://doi.org/10.1097/CHI.0b013e3181948fdd.

57. Sheeber LB, Davis B, Leve C, et al. Adolescents' relationships with their mothers and fathers: associations with depressive disorder and subdiagnostic symptomatology. J Abnorm Psychol. 2007;116:144-54. https://doi.org/10.1037/0021-843X.116.1.144.

58. Dmitrieva J, Chen C, Greenberger E, Gil-Rivas V. Family relationships and adolescent psychosocial outcomes: converging findings from eastern and western cultures. J Res Adolesc. 2004;14:425-47. https://doi.org/10.1111/j. 1532-7795.2004.00081.x.

59. Susser E, Widom CS. Still searching for lost truths about the bitter sorrows of childhood. Schizophr Bull. 2012;38:672-5. https://doi.org/10.1093/schbul/ sbs074.

60. Kelleher I, Keeley H, Corcoran P, et al. Childhood trauma and psychosis in a prospective cohort study: cause, effect, and directionality. Am J Psychiatry. 2013;170:734-41. https://doi.org/10.1176/appi.ajp.2012.12091169.

61. Zivin K, Eisenberg D, Gollust SE, Golberstein E. Persistence of mental health problems and needs in a college student population. J Affect Disord. 2009; 117:180-5. https://doi.org/10.1016/j.jad.2009.01.001.

62. Ibrahim AK, Kelly SJ, Adams CE, Glazebrook C. A systematic review of studies of depression prevalence in university students. J Psychiatr Res. 2013;47:391-400. https://doi.org/10.1016/j.jpsychires.2012.11.015.

63. Cuijpers $P$, Cristea IA, Ebert DD, et al. PSYCHOLOGICAL TREATMENT of DEPRESSION in COLLEGE STUDENTS: a METAANALYSIS. Depress Anxiety. 2016;33:400-14. https://doi.org/10.1002/da.22461.

\section{Submit your next manuscript to BioMed Central and we will help you at every step:}

- We accept pre-submission inquiries

- Our selector tool helps you to find the most relevant journal

- We provide round the clock customer support

- Convenient online submission

- Thorough peer review

- Inclusion in PubMed and all major indexing services

- Maximum visibility for your research

Submit your manuscript at www.biomedcentral.com/submit

) Biomed Central 